\title{
FRAGMENTOS DE UNA MEZQUITA SEVILLANA: LA ALJAMA DE IBN ADABBAS
}

\author{
POR RAFAEl CÓMEZ RAMOS
}

\begin{abstract}
La Mezquita aljama de Ibn Adabbas (829), la fundación islámica más antigua de Sevilla, carece de modernos estudios de arqueólogos e historiadores de la arquitectura. Mientras tanto, el historiador del arte puede formular algunas hipótesis acerca del monumento en los escasos restos que quedan de él y la evidencia de las aldabas de su puerta principal.

The Great Mosque of Ibn Adabbas (829), the oldest islamic foundation in Seville, lacks modern archeological and architectural studies. In the meanwhile, the art historian is able to formulate some hypothesis about the history of the monument through rares remains, giving new arguments and the evidence of the knockers of the main door.
\end{abstract}

La más antigua fundación islámica de Sevilla, la mezquita aljama de Ibn Adabbas, mezquita mayor de la ciudad desde el siglo IX hasta la edificación de la mezquita mayor almohade en el siglo XII, necesita nuevos estudios de arqueólogos y arquitectos que mediante reconstrucciones planimétricas iluminen lo que hasta ahora conocemos, determinando algunos aspectos. Mientras tanto, el historiador del arte puede esbozar ciertas hipótesis a través de los escasos fragmentos que restan de su efímera existencia, ofreciendo nuevos elementos de juicio que derivan del testimonio incontestable de su cultura material y quedan reflejados en las dos aldabas que lucía su puerta principal.

\section{I}

El venerable santuario -la "al-Muharram", la Sagrada, según la denominación de los cronistas musulmanes- fue fundado por orden del emir Abd al-Rahmán ibn al-Hakam, o sea, Abd al-Rahmán II, bajo la dirección del cadí Umar ibn Adabbas quien mandó las obras de edificación en el año 829-830 (214 de la Hégira) ${ }^{1}$.

1. L. Torres Balbás, "La primitiva mezquita mayor de Sevilla" Al-Andalus, XI, 1946, pp. 425-439; M. Ocaña, "La inscripción fundacional de la Mezquita de Ibn Adabbas de Sevilla", Al Andalus, XII, 1947, pp. 145-151; F. Hemández Giménez, El alminar de Abd al-Rahonán III en la Mezquita mayor de Córdoba Génesis y repercusiones, Granada, 1975, pp. 151-181; M. Valor Piechotan, "La mezquita de Ibn Adabbas de Sevilla Estado de la cuestión", Esnudios de Historia y Arqueología medievales, Universidad de Cádiz, IX, 1993, pp. 299-314. 
Siempre estuvo la primitiva mezquita mayor sevillana envuelta en una nube de misterio y milagro. Abd al-Rahmán II soñó que al entrar en el oratorio veía el cuerpo del Profeta muerto y amortajado junto al muro de la quibla. Este sueño fue interpretado como la extinción de la religión islámica en aquél lugar. Más tarde, en el 844 (230) cuando los normandos invadieron Sevilla, dispararon flechas incendiarias contra la mezquita sin conseguir destruirla. Obstinados en el intento, reunieron esteras y tablas con objeto de prender fuego que llegara al techo, no obstante, un hermoso mancebo salió del mihrab y los expulsó del recinto sagrado impidiendo que en tres días se acercaran allí, al cabo de los cuales fueron derrotados y huyeron de la ciudad ${ }^{2}$. Dejando aparte el aspecto mítico y legendario de esta relación, el hecho es que el primer santuario islámico de la ciudad de Sevilla no ardió por las razones que fuese y desde entonces estuvo nimbado de un carácter extraordinario y sobrenatural.

Asimismo, resistió a los terremotos pues en el ocurrido en 1079 (472) cayó sólo la parte alta de su alminar que fue reconstruida por orden del rey poeta al-Mutamid en el término de un mes ${ }^{3}$. Posteriormente, el crecimiento demográfico de la urbe andalusí en la segunda mitad del siglo XII durante el gobierno almohade promovió la construcción de una nueva mezquita mayor emprendida por Abu Yaqub Yusuf en 1172. Sin embargo, ésto no significó el olvido de la venerable y primitiva aljama sevillana pues el místico Ibn Arabi de Murcia y el piadoso Abu-l-Abbas Ahmad b. Ibrahim b. Mutarrif de Almería pidieron al siguiente califa Abu Yusuf Yaqub al-Mansur su restauración. Las obras fueron efectuadas en 1195 (592), reparándose el interior y el exterior del edificio, reconstruyéndose las partes ruinosas y mejorando notablemente en su totalidad. Con la reconquista de la ciudad se transformó en iglesia colegial del Salvador y conservó la misma tradición sobrenatural de antaño pues se decía que el alminar había sido construido con los sillares del templo donde estuvo el sepulcro de San Isidoro por lo que el almuédano que convocaba a los musulmanes a la oración perdía el habla y, algunas veces, también la vida ${ }^{4}$.

La mezquita tenía once naves perpendiculares al muro de la quibla y era un hermoso edificio que respondía a la características de los oratorios patrocinados por Abd al-Rahmán II ${ }^{5}$, siguiendo aquí "pari passu" el modelo cordobés dada la importancia cultural y política de la vieja capital hispalense. Era más ancha que larga y el muro de la quibla estaba orientado hacia el Sur igual que en Córdoba mientras que su oratorio consistía en una sala hipóstila cuyas naves quedaban divididas por columnas procedentes de antiguos edificios, abriendo al sahn o patio de abluciones en cuyo muro Norte se alzaba el alminar junto a la puerta que

2. L. Torres Balbás, op. cit., p.428.

3. L. Torres Balbás, Ibidem, p.429.

4. Ibídem, p. 432

5. L. Torres Balbás, op. cit., p. 434; F. Hernández Giménez, op. cit., p. 173; L. Torres Balbás, Arte Califabn "Historia de España" dirigida por R. Menéndez Pidal, t. V, Madrid, 1957, pp. 373-379; A. Jiménez, "Compendio de arquitectura emiral cordobesa" in K.A.C. Creswell, Compendio de arquitectura paleoislámica, Sevilla, 1979, pp. 485-486. 
posiblemente conectara con el eje longitudinal del edificio correspondiente con la nave medial que enfilaba hacia el mihrab.

\section{II}

El punto que puede suscitar mayor discusión a la hora de la reconstrucción ideal de este edificio reside en la cuestión acerca del número de naves. Torres Balbás y Hernández Giménez apoyándose en los cronistas musulmanes afirmaron la existencia de once naves dudando de las ocho naves que menciona el informe realizado por el maestro mayor de la diócesis, Esteban García, al derribar la mezquita en $1671^{6}$. Recientemente, Magdalena Valor ha planteado el estado de la cuestión basándose en la crónica de Ibn Sahib al-Sala y en el testimonio incontestable del maestro mayor Esteban García que vio y contó ocho naves ${ }^{7}$.

Sabido es lo dificultoso de la interpretación de los textos de los cronistas árabes a la hora de poner en conexión sus noticias con los restos arqueológicos con objeto de explicar la arquitectura islámica. Ahora bien, si recordamos que el fundador de la mezquita aljama sevillana, Abd al-Rahmán II, al emprender la ampliación de la mezquita de Córdoba mandó construir dos galerías de saqifas en las naves extremas (oriente y poniente) y otra al norte con objeto de aumentar el espacio del oratorio destinado a las mujeres ${ }^{8}$, parece lógico pensar que en Sevilla haya podido ocurrir lo mismo, dado que la nueva fundación sevillana seguiría el modelo de la capital cordobesa.

Por otra parte, asimismo, conviene tener presente la vieja polémica acerca de las supuestas naves extremas añadidas a la mezquita de Córdoba en tiempos de Abd al-Rahmán II. La discusión sobre el número de naves originada al tratar de conciliar los datos documentales con los testimonios arqueológicos fue solventada por Gómez Moreno con la verosímil hipótesis según la cual las dos naves extremas de la mezquita de Abd al-Rahmán I, destinadas al rezo de las mujeres, estaban separadas por medio de celosías de yeso o ladrillo que serían posteriormente derribadas por Abd al-Rahmán II, alcanzando la sala de oración entonces las once naves originarias ${ }^{9}$. De este modo tendría explicación la construcción de una galería septentrional que armonizara con las dos extremas o saqifas antes mencionadas.

En nuestro caso podemos pensar que nos enfrentamos ante un problema algo similar. No poseemos suficientes argumentos para dudar de la capacidad de cálculo de todo un maestro mayor del arzobispado de Sevilla como Esteban García cuando nos dice que la mezquita transformada en iglesia del Salvador

6. E. Llaguno, Noticias de los arquitectos y arquitectura de España desde su restauración, con adiciones de A. Ceán Bermúdez, t. IV, Madrid, 1829, pp. $63-$

7. M. Valor Piechotta, op. cit., p. 303.

8. L. Torres Balbás, Arte califal, pp. 388.

9. L. Torres Balbás, op. cit., pp. 388-393. 
tiene "labradas ocho naves con pilares de mármol, que corren a lo ancho" ${ }^{10}$, es decir, ocho naves separadas por columnas de mármol que van del muro Norte al muro Sur en el sentido contrario al de la orientación de la iglesia cuyo eje longitudinal invierte el primitivo espacio basilical de la mezquita.

El espacio interno de la aljama de Ibn Adabbas estuvo organizado originariamente en once naves de las cuales las dos extremas a Oriente y Occidente estaban destinadas a saqifas. Con la transformación de la mezquita en iglesia, estas naves extremas serían ocupadas por capillas como aconteció en las mezquitascatedrales de Córdoba y Sevilla y cuya disposición podemos comprobar hoy día. Probablemente, la cabecera de la iglesia, o sea, el presbiterio de la liturgia cristiana ocupara dos naves con lo cual Esteban García contó correctamente ocho naves a lo ancho sin sumar las tres restantes que, de hecho, ya no existían para el espacio cristiano.

De cualquier manera toda hipótesis que formulemos estará sujeta a los datos que proporcione la arqueología ya que la única excavación efectuada ha sido la realizada por el marqués de la Vega Inclán en 1918, que no pasó de ser una mera prospección en la que se descubrieron los arcos y capiteles que hoy vemos en el patio, calculándose que las basas de las columnas se encontraban a unos tres metros por debajo de la cota actual ${ }^{11}$.

\section{III}

Así pues, habida cuenta de los datos documentales antes expuestos y hasta que ulteriores investigaciones arqueológicas proporcionen más información, hoy por hoy los únicos vestigios concretos de los cuales habrá de partir el arqueólogo y el arquitecto historiador de la arquitectura que realicen sobre el plano la reconstrucción ideal de la mezquita, son los fragmentos que a continuación comentamos:

$1^{\circ}$ - La inscripción fundacional (año 214 H. $=829-830$ J.C.) realizada sobre un fuste de mármol gris (longitud, 3,17 m.; diámetro, 0,42 m.) que se encuentra en el Museo Arqueológico de Sevilla ${ }^{12}$. La inscripción ocupa cinco líneas de caracteres cúficos de tipo arcaico que corren paralelas al eje vertical del fuste y dicen así:

"Dios tenga misericordia de Abd al-Rahmán b. al-Hakam, el emir justo, el bien guiado por Dios, el que ordenó la construcción de esta

10. E. Llaguno, op. cit., p. 63: "Tiene de largo desde la pared del arco toral del altar mayor hasta la puerta principal que está al frente de dicho altar, cincuenta y dos varas: las cuarenta y un varas y media de ellas tienen labradas ocho naves con pilares de mármol, que corren a lo ancho; $y$ armaduras por lo alto de cuartones de Flandes".

11. B. Vega, marqués de la Vega Inclán, "El patio de la Mezquita de el Salvador de Sevilla, Boletín de la Sociedad Española de Excursiones, XXVI, 1918, pp. 18-21.

12. Catálogo del Museo Arqueológico de Sevilla, II, Madrid, 1980, p. 189. 
mezquita, bajo la dirección de Umar b. Adabbas, qadí de Sevilla, en el año 214 (11-3-829/27-2-830). Y ha escrito esto Abd al-Barr b. Harun" ${ }^{13}$.

La columna a la que correspondía este fuste se hallaba en la segunda nave de la parte oriental, frente al mihrab ${ }^{14}$. Por lo tanto, sus dimensiones $(3,17 \mathrm{~m}$.) pueden ofrecernos la altura aproximada de la segunda nave del oratorio.

$2^{\circ}$ - La parte inferior de la torre campanario de la iglesia del Salvador, antiguo alminar de la mezquita aljama, antes mencionada -la más antigua conocida de época islámica en Sevilla- y que se trata de uno de los ejemplares más interesantes como antecedentes del gran alminar de Abd al-Rahmán III en la mezquita mayor de Córdoba.

Construido en sillares de piedra arenisca colocados irregularmente a soga y tizón, tiene planta cuadrada de $5,85 \mathrm{~m}$. de lado y de él perduran $11,5 \mathrm{~m}$. en altura, quedando $2 \mathrm{~m}$. por debajo del nivel del terreno actual. Interiormente se desarrolla una escalera de caracol de $0,96 \mathrm{~m}$. de ancho que gira en torno a un machón central cilíndrico de $2,24 \mathrm{~m}$. de diámetro ${ }^{15}$. Por tanto, es rectangular por fuera y circular por dentro.

Cronológicamente anterior a los alminares de la iglesias cordobesas de San Juan y Santiago, y similar a la parte baja (hasta unos $3 \mathrm{~m}$.) de la torre de la iglesia sevillana de Santa Catalina, representa un hito fundamental para la génesis del alminar en la arquitectura del Islam de Occidente pues no se conoce en Oriente ninguno de este tipo (planta cuadrada y escalera de caracol) anterior al de Ibn Adabbas (830) ${ }^{16}$.

$3^{\circ}$ - La placa de mármol blanco (alto, $1 \mathrm{~m}$.; ancho, 0,52 m.) con la inscripción conmemorativa de la restauración del mismo alminar por al-Mutamid Ibn Abbad (472 H.=1079 J.C.) en doce líneas de caracteres cúficos que siguen así:

"Basmala, tasliyya. Ha ordenado al-Mutamid ala Allah, al-Muayyad bi-Nasrillah Abul-1-Qasim Muhammad ben Abbad -prolongue Dios la asistencia que presta a su Imperio y siga dispensándole su poderosa victoria- la construcción de la parte superior de este alminar -no deje nunca de hacerse desde él la invocación del Islam- cuando acaba de ser demolido por un gran número de terremotos que tuvieron lugar la víspera del domingo al principio de Rabi I del año 472 (1-IX-1079). Se acabó con el poder y la asistencia de Dios a finales del mismo mes. Quiera Dios aceptar por esta obra sus ocupaciones generosas y le llene de favores por cada piedra -pueda asimismo construir un palacio en su Paraíso por su gracia y bondad.

13. D. Oliva, E. Gálvez, R. Valencia, "Fondos epigráficos del Museo Arqueológico de Sevilla", Al-Qantara, VI, 1984, p. 453.

14. L. Torres Balbás, "La primitiva mezquita ... " p. 427.

15. F. Hernández Giménez, op. cit., p. 177.

16. L. Torres Balbás, op. cit., p. 438. Vid también A. Jiménez, La mezquita de Almonaster, Huelva, 1975, pp. 39-40. 
"Obra de Ibrahim el marmolista, por orden del sahib al-Ahbas y tesorero Abu Umar b. Tayyib, que Dios le favorezca" ${ }^{17}$.

Esta lápida situada junto a la puerta lateral izquierda de la iglesia del Salvador nos permite preguntarnos acerca de los efectos de aquellos terremotos sobre el conjunto de la mezquita pues, si se derrumbó la parte alta del alminar raro habría sido que el desplome no hubiera afectado a la naves del oratorio.

$4^{\circ}$ - La serie de fustes y capiteles de acarreo que sostienen las arquerías de ladrillo del patio, levantadas a fines del siglo XVII o comienzos del siglo XVIII. Aun cuando este espacio con fuente en medio rodeada de naranjos se corresponda con el antiguo sahn, no podemos afirmar que aquellos pertenezcan al mismo patio que en un principio probablemente no tuvo galerías, como afirma Hernández Giménez ${ }^{18}$.

Se trata de diez columnas con capiteles romanos y visigodos, procedentes probablemente de antiguos edificios de las inmediaciones. Sabido es que el foro, la curia y la basílica romana se situaban aproximadamente entre la plaza de la Alfalfa y la del Salvador. Nada tiene de extraño, pues, que los musulmanes hayan dedicado al culto la basílica transformada en época visigoda ${ }^{19}$ hasta que, finalmente, se construyera la aljama de Ibn Adabbas.

Tres de los capiteles son visigodos y los restantes, romanos, dos de los cuales, de acanto espinoso, son de tipo oriental, labrados en la primera mitad del siglo IV, en opinión de Schlunk ${ }^{20}$. Parece posible y no resulta difícil imaginar que esta serie de bellos capiteles romanos y sus variados fustes haya podido formar parte de los que integraban la nave medial de la mezquita:

A este grupo hoy habremos de añadir también los veintidós fustes -romanos y visigodos la mayoría de ellos- ubicados en las tiendas de la Plaza del Pan (lado oriental de la manzana de la iglesia del Salvador) que quedaron al descubierto por decisión de la Comisión de Patrimonio Histórico-artístico hace unos años.

$5^{\circ}$ - Las dos aldabas de la puerta principal del edificio que en la actualidad se encuentran en la puerta de la Sala de Exposición dentro de las dependencias de la Hermandad Sacramental del Salvador ${ }^{21}$.

17. D. Oliva et alii, op. cit., pp. 173-179.

18. F. Hernández Giménez, op. cit., pp. 173-179.

19. A. Blanco Freijeiro, La ciudad antigua (De la Prehistoria a los visigodos), "Historia de Sevilla", Sevilla, 1979, pp. 132-133 y 175.

20. Apud L. Torres Balbás, op. cit., p. 432, nota 3.

21. Publicó una fotografía con un comentario M. Gomez Moreno, Arte árabe español hasta los almohades. Arte mozárabe, "Ars Hispaniae", III, Madrid, 1951, p. 330, fig. 395. Las habíamos buscado sin éxito hasta que las hemos localizado afortunadamente gracias a la información de nuestro 
Ambas son de bronce e idénticas entre sí, hallándose fijadas a las hojas de la puerta por medio de un polígono estrellado en cuyas ocho puntas abren orificios que alojan los clavos. De esta base poligonal arranca una moldura y por encima de ella un tronco de pirámide octogonal que sustenta una cabeza de felino. De la boca del animal es de donde pende la aldaba propiamente dicha, que consiste en una forma exagonal irregular pues los lados inferiores miden $6 \mathrm{~cm}$. mientras que los dos superiores que cuelgan del animal miden $7 \mathrm{~cm}$.

La base poligonal estrellada presenta decoración incisa de orlas de ataurique de clara progenie califal cordobesa que no podríamos imaginar antes de la creación de la ornamentación de los tableros parietales del Salón Rico de Madinat al-Zahra ${ }^{22}$. Tanto el tronco de pirámide como la forma exagonal de la aldaba muestran decoración de lacería relacionada con la omamentación geométrica en piedra, cerámica y pintura de distintas dependencias de los palacios califales antes mencionados ${ }^{23}$.

La cabeza del felino está finamente trabajada, con incisiones en la parte superior figurando las crines. Se trata del mismo león de hocico redondo, ojos almendrados, orejas pequeñas y corto pescuezo, que conocemos a través de - los relieves de las pilas de mármol, los motivos figurados de los botes de marfil, y que tiene su más plástico exponente en el león de bronce de Monzón de Campos, hoy en el Museo del Louvre ${ }^{24}$.

No conocemos ninguna aldaba semejante a esta y, dentro de este género de objetos, las únicas aldabas que ocupan un lugar destacado en la historia del arte hispano-musulmán son las almohades que cuelgan de la puerta de la mezquita aljama, hoy puerta del Perdón de la Catedral de Sevilla ${ }^{25}$. Singularmente, las cabezas de las aldabas de la aljama de Ibn Adabbas ofrecen cierta similitud con las cabecitas de león de las que penden las anillas del mortero de bronce del Museo Balaguer de Villanueva y Geltrú ${ }^{26}$. Asimismo, las orlas de ataurique de la base de las aldabas sevillanas muestran semejanza con decoración del mismo tipo distribuida verticalmente en los salientes del cuerpo del mencionado mortero.

compañero el profesor José Roda Peña a quien desde estas páginas reiteramos nuestro agradecimiento. No se ven desde fuera ya que se cambiaron de la puerta exterior a la puerta interior de dicha Sala de la Hermandad Sacramental en 1974. Las dos aldabas han sido barnizadas al mismo tiempo que las puertas, lamentablemente.

22. Ch. Ewert, "Elementos decorativos en los tableros parietales del Salón Rico de Madinat alZahra", Cuadernos de Madinat al-Zahra, I, Córdoba, 1987, pp. 27-60.

23. L. Torres Balbás, Arte califal, pp. 707-713.

24. Vid Al-Andalus. Las artes islámicas en España, ed. de J. D. Dodds, Madrid, 1970, passim, p. 270, y sobre su significado R. Cómez, "Un tema iconográfico oriental antiguo en el arte hispanomusulmán del siglo XI", Homenaje al Profesor Hernández Díaz, Universidad de Sevilla, 1982, recogido después en Imagen y símbolo en la Edad Media andaluza, Sevilla, 1990, pp. 15-34.

25. L. Torres Balbás, Arte almoravide y almohade, Madrid, 1955, p. 46.

26. L. Torres Balbás, Arte califal, pp. 750-751. 
Aparte de este objeto cuyas características formales en alguno de sus elementos y estilísticas en su conjunto -aun cuando se trate de objetos de finalidad absolutamente diferente- son parangonables con las otras de metalistería que nos ocupan, no sabemos de ningún otro en bronce con el que pudiéramos comparar estas aldabas de excepcional originalidad y belleza por su carácter único.

Cronológicamente, habría que situarlas dentro de un amplio arco temporal a partir de la caída del Califato de Córdoba y más concretamente a comienzos del siglo XI, en el gobierno de los Amiríes, sin perjuicio de que sea una obra realizada en época de los Taifas, emuladores siempre del arte califal.

Si consideramos que durante el reinado de al-Mutamid ibn Abbad ocurrieron en Sevilla terremotos de cierta intensidad que condujeron a la reconstrucción de la parte superior del alminar en $1079^{27}$, parece posible que asimismo se hayan realizado algunas obras de consolidación en el oratorio aunque nunca de la envergadura de las emprendidas por el califa almohade Abu Yusuf Yaqub al-Mansur en 1195, habida cuenta de la actividad constructora de aquel monarca abbadí cuya munificencia promovió diversos edificios convirtiéndose en generoso mecenas de las artes. ${ }^{28}$

Pues bien, admitida esta hipótesis, a esas pequeñas obras de consolidación efectuadas por al-Mutamid en 1079, habría que añadir la donación de unas puertas en las que lucían estas espléndidas aldabas, dado que sus caracteres estilísticos responden al arte califal o su secuencia en el arte taifa pero no al arte emiral.

Finalmente, habiendo desaparecido la mezquita aljama de Ibn Adabbas casi en su totalidad, la imagen más clara y completa que podamos tener de ella es la concisa descripción que hizo el sevillano Francisco José Tirado de Aldana en 1726, que vio el templo antes de ser derribado y presentaba las siguientes pruebas por las que el edificio demolido había sido antigua mezquita:

"Era más ancha que larga, costumbre de los moros en sus mezquitas. La segunda por lo hondo y soterrado, pues por calle de Culebras avía una escalera tosca, sin reparo ni adorno, de 22 escalones; por la parte de la plaza tenía otros, aunque no tantos, en las puertas que tenía la fachada principal de la iglesia y la del patio de los naranjos por la puerta de la torre siempre se bajaba cuesta abajo al patio, y deste dos escalones a la iglesia. La tercera por lo lóbrego y oscuro, pues sus columnas de mármol eran de la altura de un

27. Vid nota 17.

28. J. Guerrero Lovillo, "Al-Qasr al-Mubarak, el Alcázar de la Bendición", Boletín de Bellas Artes, II, Sevilla, 1974, pp. 83-109; M'Hammad Benaboud, Sevilla en el siglo XI. El reino abbadí de Sevilla (1023-1091), Sevilla, 1992, aunque en esta traducción no se publican los aspectos que podrían interesarnos acerca de las mezquitas, los cuales pueden contemplarse a través de las páginas de $\mathrm{E}$. García Gómez y E. Lévi-Provençal, Sevilla a comienzos del siglo XII. El tratado de Ibn Abdun, Sevilla, 1992, pp. 81-92. 
hombre y no muy alto; de ellas subían dilatados arcos de ladrillo, no dejándose comunicar la luz de una nave a otra. La cuarta por ser sus lumbreras pocas y pequeñas, que en faltando el sol era necesario traer luces al coro, con estar en la nave más alta y más clara de la iglesia. La quinta por estar fabricada a forma de una bodega, con tirantes de alerze de una parte a otra. Las vidrieras mayores eran dos y caían a la plaza y por la parte de afuera qualquiera persona no muy alta llegaba con la mano a ellas, y por la parte de adentro era necesario escalera para tocarlas" 29

29. F. J. Tirado de Aldana, Templo Parroquial de Nuestro Señor San Salvador en Sevilla Apud J. Gestoso, Sevilla monumental y artística, III, Sevilla, 1892, pp. 342 y 344. 

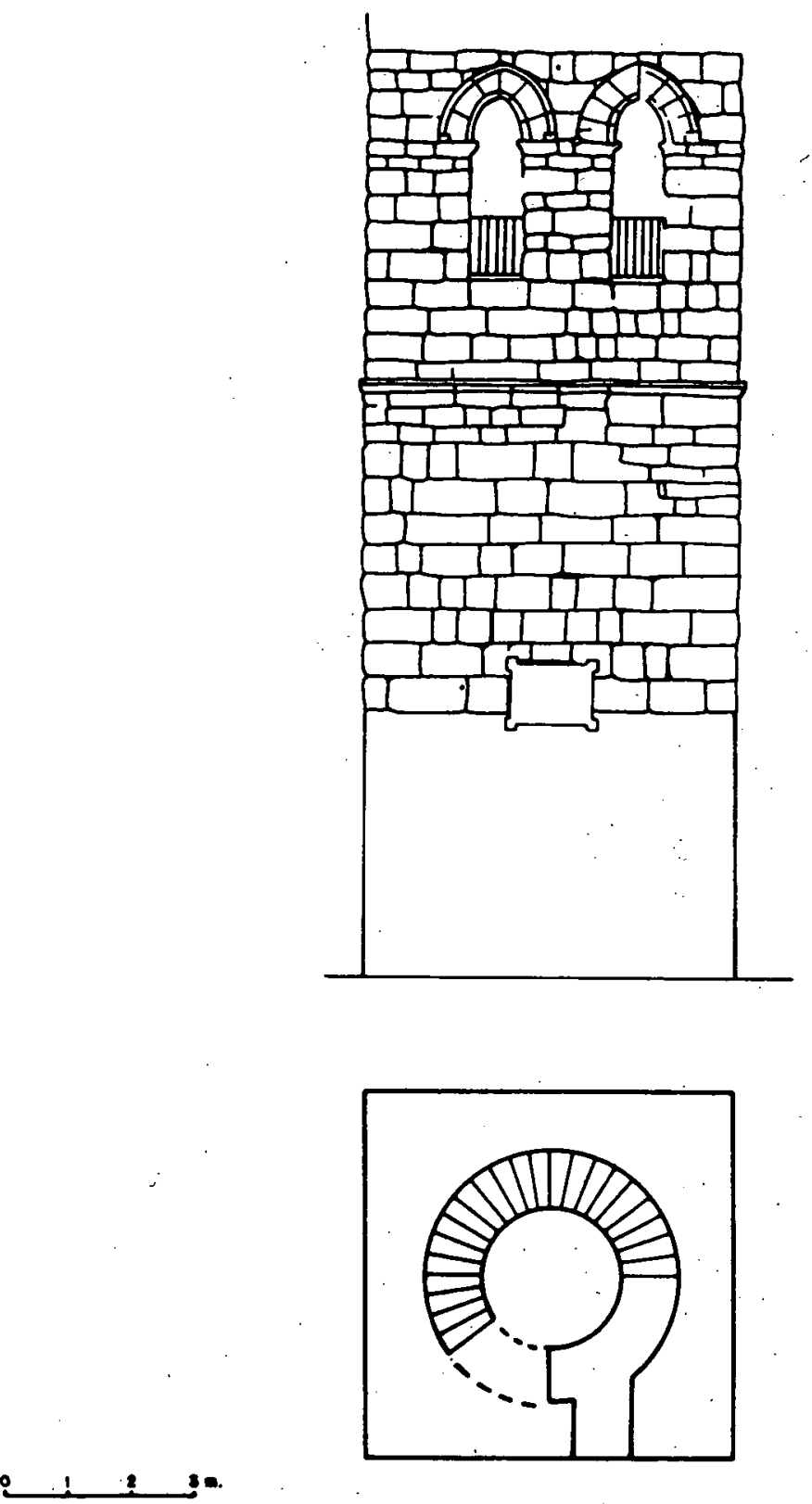

Fig. 1. Alzado y planta de la torre de la iglesia del Salvador. (L. Torres Balbás). 


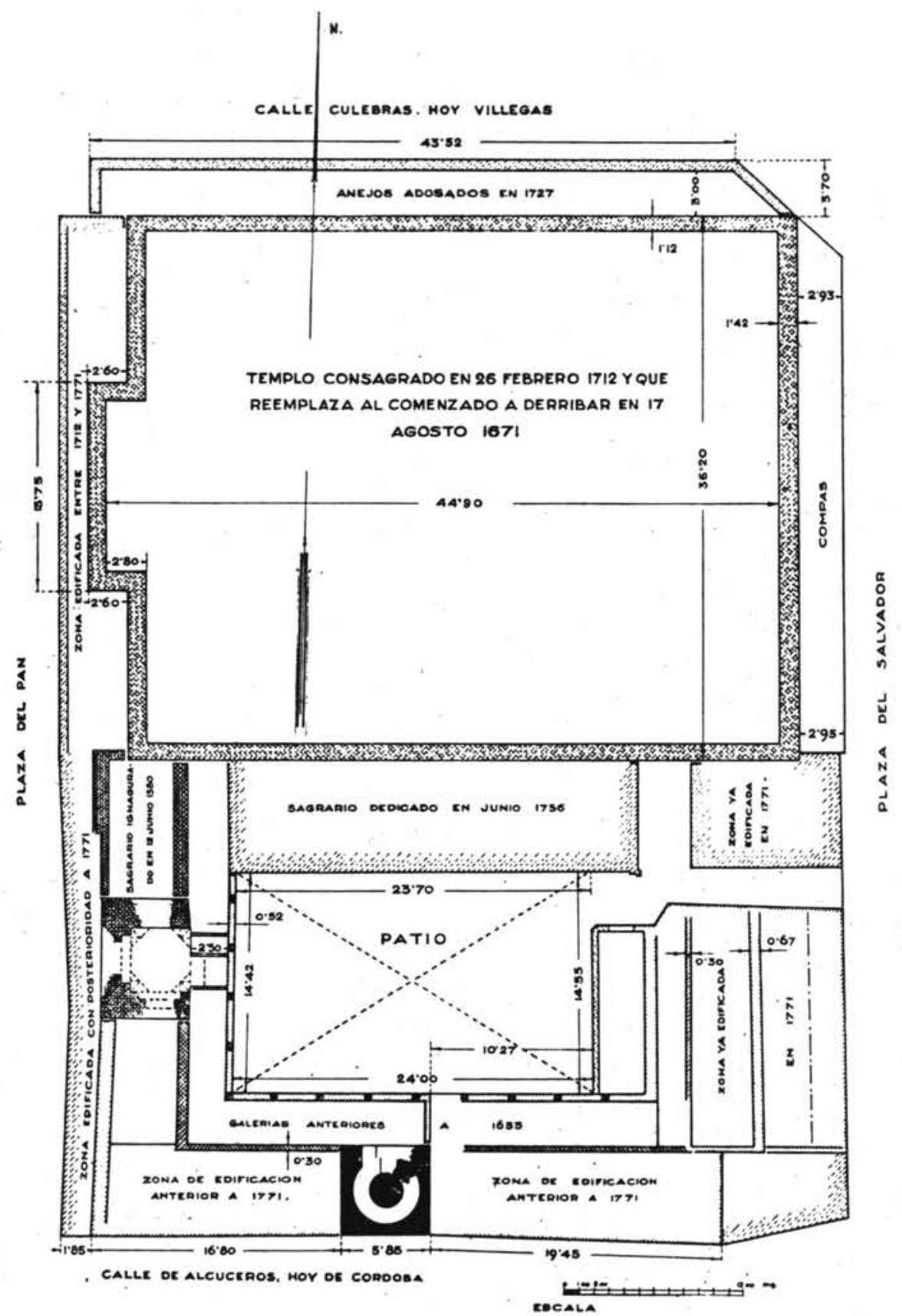

Fig.2. Planta esquemática de la manzana de la iglesia del Salvador. (Hernández Giménez). 


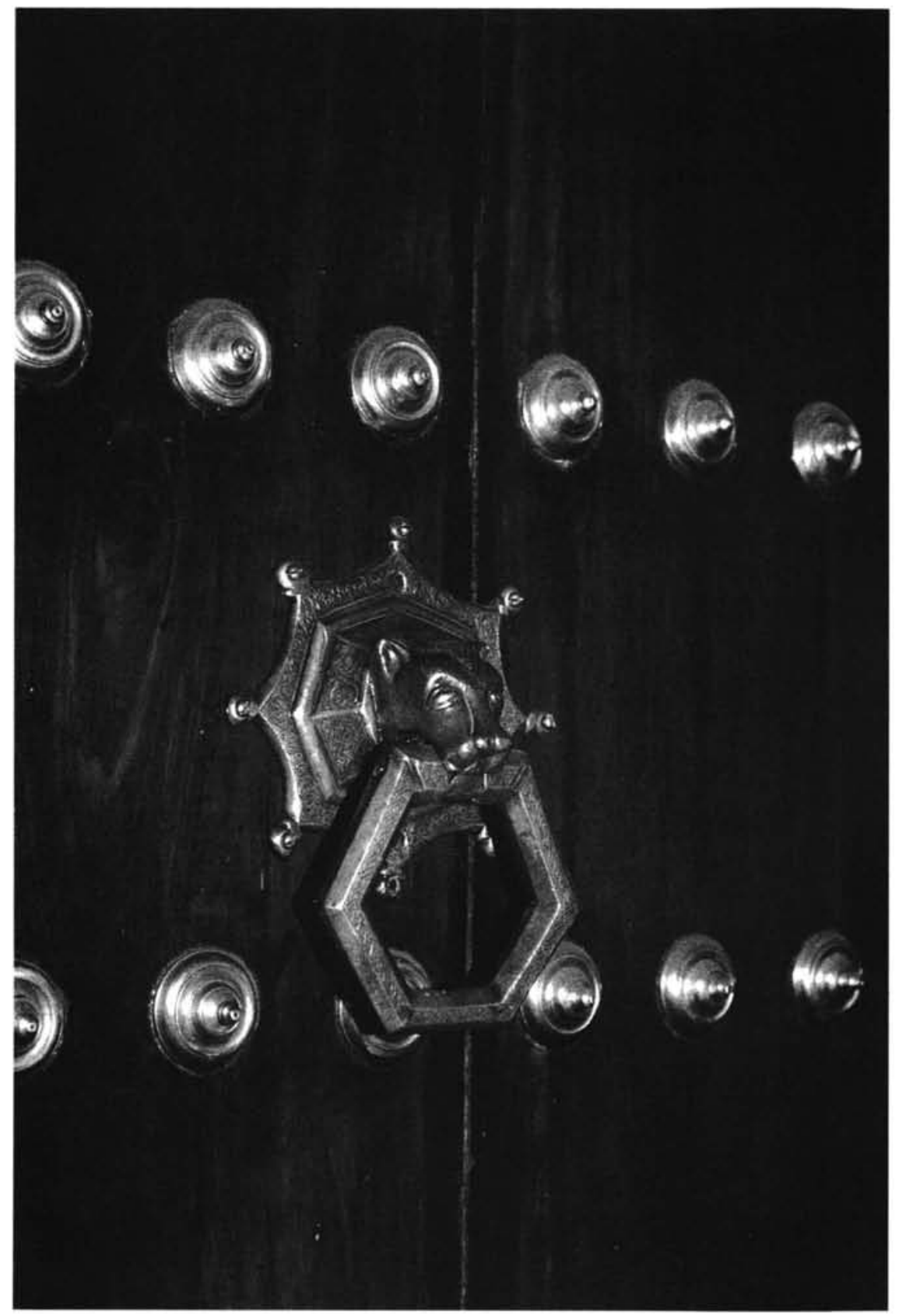

Lám. 1. Aldaba izquierda de la mezquita aljama de Ibn Adabbas. 


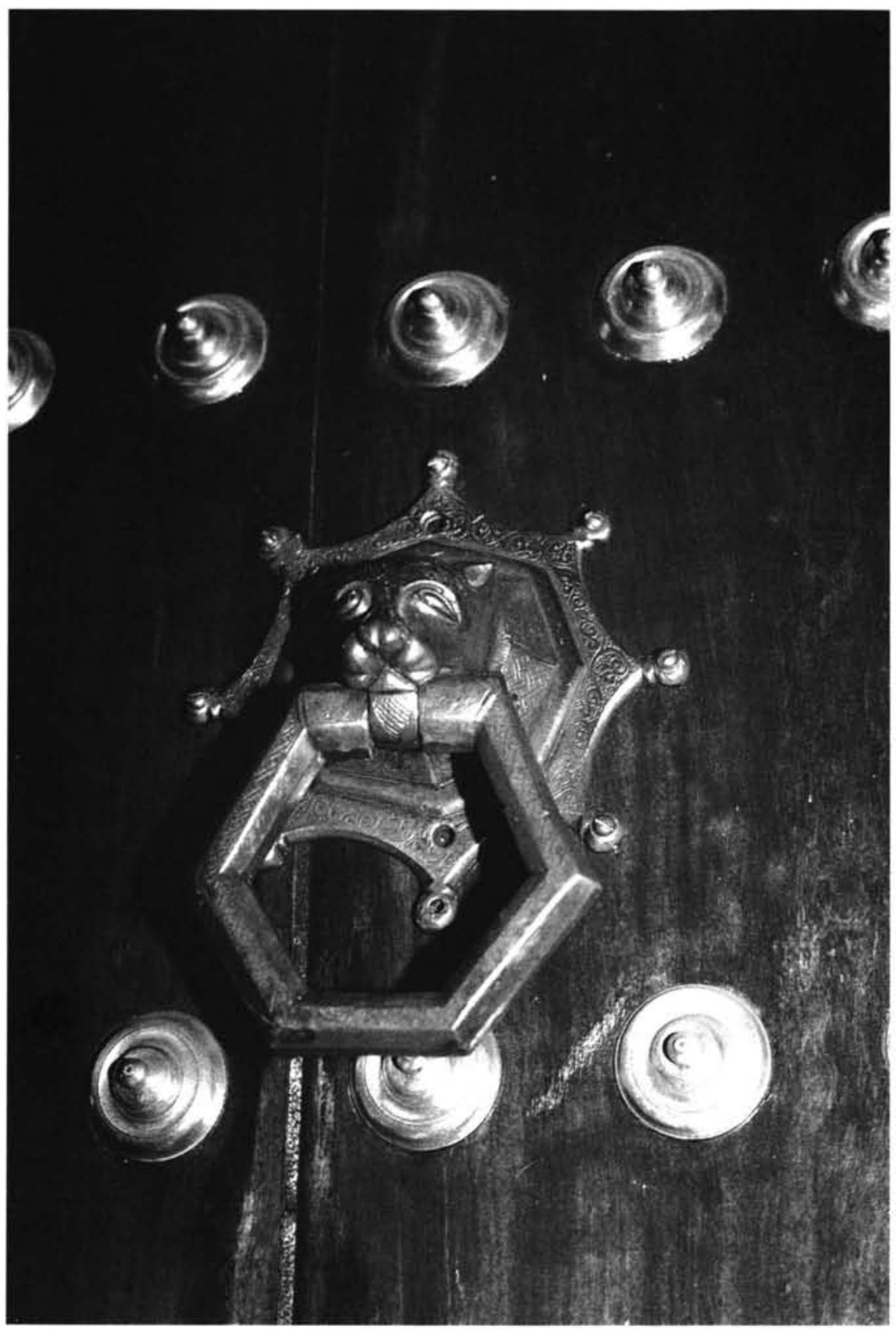

Lám. 2. Aldaba derecha de la mezquita aljama de Ibn Adabbas. 